\title{
O LÚDICO, A ESCOLA E A SAÚDE: A EDUCAÇÃO ALIMENTAR NO GIBI
}

\author{
THE PLAYFUL, THE SCHOOL, AND HEALTH: NUTRITION EDUCATION IN COMIC BOOKS
}

LO LÚDICO, LA ESCUELA Y LA SALUD: LA EDUCACIÓN ALIMENTARIA EN HISTORIETAS

\author{
Cláudia Sales de Alcântara ${ }^{1}$ \\ José Arimatea Barros Bezerra ${ }^{2}$
}

Resumo Atualmente, as histórias em quadrinhos são tratadas como ferramenta didático-pedagógica muito eficaz, com a capacidade, mediante seu currículo cultural, de divertir, sentir, viver e se comportar no mundo. Este artigo objetiva investigar o livro Almanaque Maluquinho: Julieta no mundo da culinária, reconhecendo o papel pedagógico das histórias em quadrinhos, a fim de perceber se essa publicação possibilita discussões que explorem diferentes áreas pertinentes à educação alimentar, podendo tornar-se uma estratégia para a sensibilização do tema com o público infantil. Fizemos uso da análise de discurso por ser uma ferramenta metodológica que nos conduz na interpretação dos sentidos de um texto/imagem. A análise se deu em três etapas: a do contexto narrativo, por meio da qual se tentou compreender o contexto em que os personagens do livro estão inseridos; a dos quadrinhos, para melhor entendimento dos elementos imagéticos presentes nas histórias; e a das receitas, que avaliou cada preparo contido no livro, de modo a perceber sua colaboração na discussão da educação alimentar. Por fim, a pesquisa buscou proporcionar uma sensibilização do olhar para as possibilidades de inserção da ludicidade em um campo do saber marcado pela prescrição.

Palavras-chave educação alimentar; nutrição; currículo cultural.
Abstract Comic books are currently seen as a very effective didactic and pedagogical tool, capable, through their cultural curriculum, of bringing fun, feelings, and of helping one to live and behave in the world. This article aims to investigate the Almanaque Maluquinho: Julieta no mundo da culinária (Little Crazy Almanac: Juliet in the culinary world) comic book, acknowledging the educational role comic books can play, in order to determine whether this publication enables discussions on the exploring of different areas relevant to food education and whether it may become a strategy to bring awareness on the theme to children. We used discourse analysis, as it is a methodological tool that leads us to interpret the meanings of a text/image. The analysis was done in three stages: The analysis of the narrative context, through which we tried to understand the context in which the characters of the book are inserted; analysis of comics, for a better understanding of imagistic elements featured in the stories, and analysis of the recipes, through which each preparation contained in the book was evaluated to determine its collaboration in the food education discussion. Finally, the study sought to bring awareness about the look at the possibilities of inserting playfulness in a field of knowledge marked by prescriptions.

Keywords food education; nutrition; cultural curriculum. 


\section{Introdução}

Muitas questões surgem quando o assunto é educação alimentar. A primeira é quanto ao material para auxiliar as discussões: a importância em procurar ou criar materiais para educação alimentar, suprindo a escassez de publicações com essa temática dirigida ao público infantil. Consoante pensam Barbosa, Salles-Costa e Soares (2006, p. 259), a "inexistência de guias específicos para a população infantil se deve à dificuldade nas adaptações dos conteúdos das mensagens e das porções expressas de alimentos, com o propósito de torná-los compreensíveis e motivadores".

Desenvolver ou reconhecer publicações para o público infantil é relevante para enfrentar as dificuldades de se fazer uma nova proposta de educação alimentar e nutricional, pois tais publicações facilitam a aprendizagem e a consciência crítica de se criar um comportamento alimentar saudável, que leve em consideração as especificidades e características alimentares de cada região do país. Sobre materiais voltados para o público infantil, Bizzo e Leder (2005) nos ensinam:

Quanto aos recursos didáticos de apoio, como material audiovisual, não são meros coadjuvantes e devem guardar estrita coerência com as premissas pedagógicas anteriormente referidas, constituindo-se provocativos e não meramente contemplativos, e com expressiva ênfase em imagens e esquemas didáticos que levem a pensar e não a imprimir conhecimento pronto (Bizzo e Leder, 2005, p. 663).

Por esse motivo, devemos ter muito cuidado ao selecionar uma literatura para o desenvolvimento de qualquer projeto, seja dentro, seja fora da escola. Acreditamos que as histórias em quadrinhos têm uma ludicidade que convida o leitor a fazer parte da história, proporcionando uma identificação imediata de quem lê com os assuntos ali abordados.

Este artigo apresenta resultados da análise do livro Almanaque Maluquinho: Julieta no mundo da culinária, reconhecendo o papel pedagógico das histórias em quadrinhos, com o objetivo de verificar se possibilitam discussões que explorem diferentes áreas pertinentes à educação alimentar e possam ser utilizadas como estratégia para abordar tal tema com o público infantil. Origina-se da tese de Cláudia Sales de Alcântara, intitulada Entre a razão e os sentidos, a prescrição e a experiência: Friedrich Schiller e as possibilidades de uma educação alimentar estética. A pesquisa contou com financiamento do Conselho Nacional de Desenvolvimento Científico e Tecnológico (CNPq) e não foi submetida ao Comitê de Ética por se tratar da análise de conteúdo de um livro infantil. 


\section{Histórias em quadrinhos: ferramenta pedagógica a serviço da alimentação}

As histórias em quadrinhos existem desde o início da história da humanidade como linguagem gráfica. O ser humano primitivo retratava graficamente, por meio de desenhos canhestros, nas paredes das cavernas em que habitava, as caçadas ou feitos que representavam seu cotidiano.

Atualmente, as histórias em quadrinhos são tratadas como um instrumento didático-pedagógico, portador de um currículo cultural ${ }^{3}$ que permite a reflexão sobre valores, atitudes e riqueza histórico-cultural, promovendo a valorização de nossa cultura nacional e local. A sua utilização em aulas de língua portuguesa, história, geografia, matemática, ciências, arte e educação alimentar e nutricional pode promover um aprendizado mais reflexivo e prazeroso, por meio da interdisciplinaridade e da transversalidade.

Essa perspectiva de currículo cultural tem como fundamento a ideia de cultura defendida pelos estudos culturais britânicos, da Universidade de Birmingham. Tais estudos preocuparam-se com produtos da cultura popular e dos mass media que expressam os sentidos que vem adquirindo a cultura contemporânea. Dessa forma, a concepção de currículo aqui empregada compreende todo o conhecimento na medida em que se estrutura num sistema de significado que abre possibilidades para a compreensão de que espaços como museus, cinema, televisão, músicas, shows e histórias em quadrinhos sejam considerados como instâncias culturais capazes de formar identidade e subjetividade.

Pelo seu compromisso com a sociedade, a história, a cultura e a política, o campo de estudos de currículo tem contribuído de maneira significativa para os estudos em educação, mostrando que vários produtos e práticas culturais possuem valor pedagógico. Como diz Steinberg (1997, p. 102), “lugares pedagógicos são aqueles onde o poder se organiza e se exercita, tais como bibliotecas, TV, filmes, jornais, revistas, brinquedos, anúncios, videogames, livros, esportes etc.".

Nesse sentido, toda mídia tem outros objetivos que vão além do entretenimento. Em se tratando das histórias em quadrinhos, percebemos que existe uma parcela de publicações que são voltadas para educação e treinamento, publicidade e propaganda, o que mostra a popularidade e a aceitação desse recurso na sociedade. Integram uma gama de publicações, como cartilhas, folhetos, livros e álbuns, que fazem uso da linguagem dos quadrinhos para a transmissão de conhecimentos específicos. É o que Vergueiro e Ramos (2009) chamam de quadrinhos voltados para a educação popular:

(...) de forma puramente pragmática, essas publicações lançam mão dos recursos da linguagem gráfica sequencial como instrumento para atingir mais facilmente o seu público em termos do que poderíamos chamar de educação popular - em geral, 
desvinculada dos canais formais de ensino -, incutindo-lhe ensinamentos religiosos, orientações para a utilização de serviços públicos ou privados, entre outros, que visam capacitar o cidadão à vida em sociedade. (...) essa produção quadrinística voltada à educação popular é geralmente desconhecida da maioria da população e até mesmo de boa parte dos produtores profissionais de quadrinhos. Além disso, muitos pesquisadores da área optam por ignorá-la totalmente, talvez a considerando como um objeto pouco digno de ser analisado em ambiente acadêmico (Vergueiro e Ramos, 2009, p. 89-90).

Voltando-se apenas para as publicações com fins educacionais, o Núcleo de Pesquisas de Histórias em Quadrinhos da Escola de Comunicação e Artes da Universidade de São Paulo conseguiu reunir 64 títulos desde 1990.4 Este número pode parecer pequeno com relação ao universo de publicações de histórias em quadrinhos, contudo "pode ser considerado representativo do que é feito na área de produção de quadrinhos para educação popular" (Vergueiro e Ramos, 2009, p. 91).

Das publicações selecionadas pelo Núcleo de Pesquisas de Histórias em Quadrinhos, 15 títulos (23\%) estão voltados para a área da saúde, perdendo em número de publicações apenas para os temas voltados para os recursos naturais $(34 \%)$ - o que mostra o interesse em educar a população para a saúde. O tema da alimentação é um dos aspectos abordados, para o qual o cartunista Ziraldo contribui significativamente.

Identificado com a educação brasileira, o personagem Menino Maluquinho está presente em centenas de livros didáticos e participa ativamente de numerosas campanhas institucionais do governo. Foi eleito garoto-propaganda da campanha Fome Zero e da merenda escolar durante toda a gestão do presidente Luiz Inácio Lula da Silva. Ao se considerar essa vasta publicação, destacamos alguns livros nos quais o autor trabalhou com o tema da alimentação: revista em quadrinhos Turma do Laguinho: supermercado - consumo consciente (Ziraldo e Lago, 2009a), revista em quadrinhos Turma do Laguinho: vivendo com saúde - os alimentos (Ziraldo e Lago, 2009b), Almanaque Maluquinho: Julieta no mundo da culinária (Ziraldo, 2008), O livro de 'dietas' do Menino Maluquinho (Ziraldo e Lancellotti, 2004), O livro de receitas do Menino Maluquinho (Ziraldo, 2005), cartilha Escolha, freguês (Ziraldo e Ministério do Desenvolvimento Agrário, 2005), cartilha Vamos cuidar da merenda escolar (Ziraldo e Associação de Apoio à Merenda Escolar (2006), cartilha Olho do consumidor (Ziraldo e Ministério da Agricultura, Pecuária e Abastecimento, 2009), os livros de atividades Ai, que dor de barriga! (Ziraldo, 1999) e Tô com fome (Ziraldo, 2001).

Dentre as obras nas quais o cartunista aborda o tema da alimentação, o Almanaque Maluquinho: Julieta no mundo da culinária se destaca por apresentar elementos de histórias em quadrinhos e pela possibilidade de as 
receitas serem realizadas pelas crianças. Trata-se de uma revista em quadrinhos com tudo aquilo a que se tem direito: balões, requadros etc. Não existem no seu interior textos explicativos, nem tabelas ou gráficos. Voltada para o público infantil, a publicação encanta pelo colorido, pelo ritmo e pelos textos leves e de fácil compreensão. O próprio autor - que dispensa as parcerias para esse trabalho - explica:

Muita gente por aí acha que culinária é assunto para adultos, que só pessoas maduras têm sensibilidade para apreciar um paladar raro e exótico ou a combinação exata de temperos de um prato típico. Mas criança adora culinária! As meninas e meninos é que gostam de botar a mão na massa, de fazer misturas malucas e sujar o avental, de provar gororobas e de ver o fogo transformar os alimentos, tal como numa experiência de mágico ou de feiticeiro (Ziraldo, 2008, p. 3).

O livro possui sete histórias curtas, destinadas a crianças, que abordam os seguintes temas: consumo, memória gustativa, comida vegetariana, economia e outros assuntos pertinentes ao campo da alimentação. Entre as histórias, o leitor pode se deliciar com seis receitas, apresentadas por Julieta numa espécie de talk show.

A obra torna-se interessante pelo seu caráter lúdico, pela qualidade gráfica e principalmente por não ser um livro tido como manual, ou cartilha. Ao mesmo tempo, essa publicação se aproxima da temática da alimentação e convida as crianças a se tornarem sujeitos de sua aprendizagem.

\section{Almanaque Maluquinho: Julieta no mundo da culinária - interpretando para melhor usar}

Acreditamos ser importante tentar entender e explicar como se efetiva a articulação entre imagem e texto, e como esses códigos se relacionam com a sociedade. Para isso, utilizamos a análise do discurso (AD) como um instrumento para se refletir sobre a estrutura e o sentido da revista em quadrinhos Almanaque Maluquinho: Julieta no mundo da culinária.

A AD é uma ferramenta metodológica que nos conduz na interpretação dos sentidos de um texto/imagem, desvelando sua estrutura. É “um método para analisar, refletir sobre o discurso. Pertencente à semiologia, ela quer chegar à reconstituição do sentido produzido para entendê-lo" (Galvão, 2007, p. 3). Pode ser definida como "teoria da determinação histórica dos processos semânticos" (Pêcheux e Fuchs, 1990, p. 164, apud Mariani, 1998, p. 27). Esses processos semânticos percebem que sentido e sujeito são resultantes inacabados de um processo histórico-social, imersos em constituições e contradições. 
A análise do discurso surgiu em 1960, na França, com o objetivo de estudar as relações estabelecidas entre o discurso, os indivíduos que a utilizam e o contexto em que se desenvolve o dizer. Estuda as visões de mundo inscritas no discurso, fazendo uma reflexão sobre a língua e sua interpretação, sendo assim muito mais do que uma técnica de comentário de texto. De acordo com Orlandi (2001), a AD nos ajuda a

Problematizar as maneiras de ler, levar o sujeito falante ou o leitor a se colocarem questões sobre o que produzem e o que ouvem nas diferentes manifestações da linguagem. Perceber que não podemos não estar sujeitos à linguagem, a seus equívocos, sua opacidade. Saber que não há neutralidade nem mesmo no uso mais aparentemente cotidiano dos signos. A entrada no simbólico é irremediável e permanente: estamos comprometidos com os sentidos e o político. Não temos como não interpretar. Isso, que é a contribuição da $\mathrm{AD}$, nos coloca em estado de reflexão e, sem cairmos na ilusão de sermos conscientes de tudo, permite-nos, ao menos, sermos capazes de uma relação menos ingênua com a linguagem (Orlandi, 2001, p. 9).

Por intermédio da $\mathrm{AD}$, podemos questionar os sentidos fixados nas mais variadas formas de produção - verbais (oral e escrita) e não verbais (imagens). Analisar um enunciado não se limita a observar sua estrutura gramatical, mas significa perceber os elementos históricos, sociais, culturais e ideológicos que o envolvem.

Não é objetivo da análise discursiva emitir julgamento de valor sobre um discurso; logo, ela não tem a pretensão de mostrar o que é certo ou errado. Caregnato e Mutti (2006) acrescentam:

A AD trabalha com o sentido e não com o conteúdo do texto, um sentido que não é traduzido, mas produzido; pode-se afirmar que o corpus da AD é constituído pela seguinte formulação: ideologia + história + linguagem. A ideologia é entendida como o posicionamento do sujeito quando se filia a um discurso, sendo o processo de constituição do imaginário que está no inconsciente, ou seja, o sistema de ideias que constitui a representação; a história representa o contexto sócio-histórico e a linguagem é a materialidade do texto gerando 'pistas' do sentido que o sujeito pretende dar. Portanto, na $\mathrm{AD}$ a linguagem vai além do texto, trazendo sentidos pré-construídos que são ecos da memória do dizer (Caregnato e Mutti, 2006, p. 680-681).

Ao interpretar um discurso, devemos ter em mente a ideia de que quem analisa também é um intérprete que lê o texto, influenciado por suas crenças, valores, experiências vividas, afetos etc. Nesse sentido, a interpretação jamais será única e absoluta, assim como nunca será neutra. Quanto a esse aspecto da análise do discurso, Caregnato e Mutti (2006) advertem: 
A AD não vai trabalhar com a forma e o conteúdo, mas irá buscar os efeitos de sentido que se pode apreender mediante interpretação. Nunca esquecer que a interpretação sempre é passível de equívoco, pois embora a interpretação pareça ser clara, na realidade existem muitas e diferentes definições, sendo que os sentidos não são tão evidentes como parecem ser (Caregnato e Mutti, 2006, p. 680-681).

Embora a AD seja mais utilizada nos estudos e pesquisas no campo das ciências da linguagem, ela se torna cada vez mais relevante no campo das ciências humanas em geral. Por isso, decidimos utilizá-la na interpretação do Almanaque Maluquinho: Julieta no mundo da culinária, estruturando a análise em três partes: a do contexto narrativo, na busca de compreender em que contexto histórico e cultural surge o Menino Maluquinho e os demais personagens; a dos quadrinhos, percebendo como alguns recursos visuais, tais como cor, enquadramento, ângulos e objetos que influenciam na leitura da história - uma história em quadrinhos -, oferecem muitas possibilidades que são importantes na elaboração da narrativa e conduzem o leitor na interpretação da história, sendo relevantes para entender seus elementos visuais; e a das receitas do livro, a fim de realizar uma observação qualitativa das receitas com o objetivo de perceber se estas poderiam possibilitar a discussão de diferentes temas pertinentes à educação alimentar.

\section{O contexto narrativo}

Em 1980, Ziraldo criou um personagem que se tornou o mais popular de toda a sua produção: o Menino Maluquinho. Ele não tem um nome, pois pode ser qualquer criança, e é caracterizado por Ziraldo (2009, p. 3-8) pelos seguintes jargões: "tinha o olho maior do que a barriga [p. 3], tinha fogo no rabo [p. 4], tinha vento nos pés [p. 5], umas pernas enormes (que davam para abraçar o mundo) [p. 6] e macaquinhos no sótão [p. 7] (...). Ele era um menino impossível! [p. 8]"

A 'maluquice' do menino vem do fato de ele quebrar o estereótipo esperado das crianças nas décadas de 1950 e 1960, que deveriam ser submissas, obedientes e boazinhas, não questionavam os adultos, aceitavam tudo sem questionar 'por respeito' aos mais velhos. O Menino Maluquinho contrapõe esse estereótipo desejado. É uma criança questionadora, dando sua opinião de forma crítica (mesmo sem ter sido solicitada), inquieta, insaciável, ativa, veloz e cheia de vontade de viver intensamente a sua infância.

As histórias em quadrinhos desse personagem e a sua turma foram criadas somente oito anos depois do seu 'nascimento', em 1988, voltadas para um público infantil mais exigente e curioso: as crianças de classe média da década de 1990. A turma do Menino Maluquinho é composta de três 
meninas - Julieta, Carolina e Shirley Valéria - e cinco meninos - Maluquinho, Bocão, Lúcio, Junim e Herman. São crianças que frequentam a escola, fazem uso das tecnologias, têm uma família tradicional, acompanham os fatos políticos do país. Crianças privilegiadas que têm sua infância respeitada, com direito a fantasia, brincadeiras, carinho e atenção.

Além dos personagens infantis, aparecem, principalmente, os pais do Menino Maluquinho. O pai do Maluquinho é um pai de família tradicional, provedor do lar; um arquiteto competente e trabalhador. A mãe, por sua vez, apesar de ser graduada em psicologia, vive para os afazeres do lar; está sempre na cozinha e usa avental.

No Almanaque Maluquinho: Julieta no mundo da culinária, todos esses personagens aparecem para mostrar que as crianças podem transformar a cozinha - lugar visto como perigoso - em um local lúdico, onde se divertem enquanto preparam deliciosas receitas. Foram selecionadas as seis receitas do talk show 'A cozinha de Julieta' para serem analisadas. Nessa história, podemos perceber as ideias que os personagens têm em torno do tema da alimentação. É um convite para que o leitor experimente a realidade vivida pelos personagens e se sinta parte dessa turma. Todas as histórias são carregadas de humor, mostrando o cotidiano da classe média de forma otimista e esperançosa, em uma sociedade repleta de contradições.

\section{Análise dos quadrinhos}

Em todas as receitas, Julieta e a Turma do Menino Maluquinho comportam-se como crianças, tornando o ato de cozinhar uma brincadeira divertida. Enquanto Julieta prepara as receitas (algumas com a ajuda de sua mãe), a turma simula a filmagem de um programa de televisão, uma espécie de 'Ana Maria Braga', o talk show 'A cozinha de Julieta'.

$\mathrm{O}$ autor (Ziraldo) utiliza ainda a coloração laranja nas páginas desse talk show para servir como fundo para os quadros. Laranja é uma cor que incita a criatividade e está relacionada à alimentação (podendo ser vista principalmente nas embalagens de gêneros alimentícios). Essa tonalidade

tem como benefícios o entusiasmo, a vivacidade, a alegria de ser expansivo e afirmativo. A comunicação também é beneficiada por esta cor, que também transmite a sensação de movimento e gera iniciativa com criatividade e alegria. É a cor que fortalece laços fraternos, pois transmite sensações de confiança, coragem, animação, espontaneidade e atitude positiva frente à vida (Valdir, 2005, p. 37).

Lüscher, um dos maiores pesquisadores sobre cores, diz ainda que o laranja está relacionado ao desejo, a todas as formas de ânsia e ao apetite 
insaciável. Seu conteúdo emocional é o desejo, e sua percepção sensorial é o apetite. O psicólogo Bamz, em estudo sobre a relação entre a idade de um indivíduo e a sua preferência por uma determinada cor, identificou o fato de que o laranja - cor da aventura, excitação e imaginação - é preferência das pessoas de dez a vinte anos de idade, ou seja, um público infantojuvenil (Freitas, 2007). Percebemos que o uso das cores não é ingênuo, tampouco tem função meramente decorativa; elas exercem grande influência física e psicológica nas pessoas.

Quase todos os enquadramentos se desenvolvem usando o plano total, que permite uma fluidez na leitura, em uma diagramação que usa o ângulo médio de visão, ou seja: todas as personagens estão na altura dos olhos do leitor, o que transmite a sua equidade. Ressaltamos que, apesar de as histórias mostrarem a importância de se alimentar, não encontramos imperativos, nem prescrições. Tudo acontece de forma leve e informativa, conduzindo o leitor a refletir sobre a importância de uma alimentação diversificada.

A maioria das publicações sobre educação alimentar aborda essa questão como se dependesse unicamente da consciência e da 'boa vontade' de cada um. Ou seja: transfere-se para o leitor, de forma imperativa, a responsabilidade pela construção de uma vida mais saudável, pressupondo-se a modificação dos maus hábitos alimentares mediante um novo conhecimento que é repassado. Aos que não seguem as prescrições contidas no seu interior, ou por teimosia, ou por desconhecimento, ou ainda por ausência de condições possíveis de fazê-lo, resta reafirmar a sua 'incompetência e inadequação para o viver saudável'.

É interessante perceber ainda que, em todas as histórias, existe a preocupação do autor com as normas de higiene e segurança. Julieta aparece sempre trajada com luvas e avental, apesar de estar sempre de cabelos soltos (quando a mãe da personagem aparece nas histórias para auxiliá-la, também está portando luvas). E quando é preciso usar facas, forno ou outros aparelhos eletrodomésticos, há sempre a supervisão de um adulto.

\section{Análise das receitas}

Mesmo com a proposta da pesquisa sendo pedagógica, somos cientes de que a pedagogia não é um campo isolado, hermético e dissociado de outros saberes; ela dialoga com diferentes áreas do conhecimento, dentre as quais a nutrição, por isso uma análise nutricional das receitas foi importante para esta pesquisa.

Para realizar esta análise, utilizamos a Tabela Brasileira de Composição de Alimentos (Taco), de 2006 (Universidade Estadual de Campinas, 2006), com o objetivo de conhecer e disponibilizar dados sobre a composição dos 
principais alimentos contidos em cada receita. Esta tabela mostra a composição de diversos tipos de alimentos por cem gramas de parte comestível, sendo este dado "um elemento básico para ações de orientação nutricional baseadas em princípios de desenvolvimento local e diversificação da alimentação, em contraposição à massificação de uma dieta monótona e desequilibrada" (Universidade Estadual de Campinas, 2006, p. 5).

Além desse instrumento, tivemos a preocupação de pedir a orientação de um profissional da área da nutrição que pudesse avaliar qualitativamente as receitas. A preocupação nunca foi com a quantidade de calorias que cada receita possui; a inquietação nunca foi numérica. Não pretendíamos uma análise nutricional baseada em tabelas e cálculos calóricos, mas uma observação qualitativa das receitas, que primasse por uma descrição cuidadosa de cada preparo, informando suas potencialidades e seus pontos negativos (porque tudo possui dois lados). Para esse trabalho contatamos uma profissional da área da nutrição, Adriana Camurça Pontes Siqueira, nutricionista, professora do curso de gastronomia da Universidade Federal do Ceará, que se tornou colaboradora desta pesquisa.

A primeira história ensina a fazer o sanduíche rápido. Uma receita simples, a qual necessita de ingredientes que facilmente podem ser comprados em qualquer supermercado e com preço acessível (o peito de peru é o insumo mais caro do preparo). Uma receita que se ajusta bem ao paladar das crianças, mas pode causar estranhamento em razão de o alimento ser consumido frio. Isso porque as crianças, de modo geral, estão habituadas com os sanduíches preparados pelas superfranquias de hambúrgueres, tais como McDonalds, Bob's e Burger King, que têm como características serem servidos quentes, com fritura, maioneses temperadas e quase nenhuma salada, praticamente o contrário do que a receita propõe - um sanduíche frio, sem fritura, com pouca maionese e bastante salada.

A receita foi analisada como uma preparação rápida e fácil e com excelente valor nutricional, pois contém alimentos de todos os grupos. Possui o pão, rico em carboidratos (44, $1 \mathrm{~g}$ a cada $100 \mathrm{~g}$ de parte comestível), e maionese, rica em lipídios $(30,5 \mathrm{~g}$ a cada $100 \mathrm{~g}$ de parte comestível), representando os alimentos energéticos; além do peito de peru, alimento do grupo dos construtores, ou seja, rico em proteína ( $18,1 \mathrm{~g}$ a cada $100 \mathrm{~g}$ de parte comestível). A receita ainda sugere o uso do pão de centeio ou do integral, que também são ricos em fibra (o integral possui $6,9 \mathrm{~g}$ de fibras a cada $100 \mathrm{~g}$ de parte comestível, enquanto o pão de forma convencional possui $2,5 \mathrm{~g}$ ), junto com o pão branco.

Além dos ingredientes e do modo de fazer, a receita apresenta a origem do sanduíche, uma informação importante para a valorização do alimento não somente quanto ao valor nutricional e sensorial, mas também quanto a sua importância cultural. Os alimentos, a alimentação, a comida e suas formas de preparo representam também a cultura de um povo. 
A segunda receita do livro é um 'patê de atum com agrião', receita constituída por ingredientes acessíveis, de fácil preparo e para ser consumida fria. $\mathrm{O}$ atum e o agrião são os principais insumos: o atum é um peixe que a maioria das crianças brasileiras já experimentou, se não na sua forma in natura, ao menos na sua forma industrializada, em conserva; já o agrião, uma hortaliça conhecida por suas propriedades medicinais, não faz parte da alimentação popular.

$\mathrm{O}$ atum é um peixe muito apreciado pelos brasileiros; além de ser rico em proteína $(26,2 \mathrm{~g}$ a cada $100 \mathrm{~g}$ de parte comestível), ele contém ferro, fósforo, magnésio, selênio, niacina, vitaminas B6 e B12; é ótima fonte de ômega 3, ácido graxo essencial que protege o coração das doenças cardiovasculares. $\mathrm{O}$ agrião é rico em enxofre, potássio, cálcio, fósforo, magnésio, cloro, sódio e ferro, além das vitaminas A, B1, B2 e C, nutrientes importantes para o crescimento e o desenvolvimento das crianças. A receita combina esses insumos de forma simples, mas que consegue disfarçar o sabor do agrião, o qual muitas vezes é rejeitado pelas crianças, melhorando sua aceitação e consumo.

A receita que se segue chama-se 'barquinhos de ricota'. É o preparo mais caro do livro, pois a ricota é um queijo de custo alto e não encontrado com tanta facilidade. A realização é relativamente fácil, mas exige que um adulto esteja por perto, pois necessita de forno. Combina alimentos dos três grupos: o pão, do grupo dos energéticos; a ricota, do grupo dos alimentos proteicos $(12,6 \mathrm{~g}$ de proteína a cada $100 \mathrm{~g}$ de parte comestível), conhecidos como construtores, e também rica em cálcio $(253 \mathrm{mg}$ a cada $100 \mathrm{~g}$ de parte comestível); ainda estão presentes o orégano, o tomate e a cebola, do grupo dos reguladores, ricos em vitaminas e minerais. Por fim temos o azeite, fonte de vitamina E, que também está no grupo dos energéticos. É rico em gordura monoinsaturada $(75,5 \mathrm{~g}$ a cada $100 \mathrm{~g}$ de parte comestível) e de compostos fenólicos, antioxidantes que protegem as células dos radicais livres, os quais podem causar, entre outros problemas, o envelhecimento precoce e doenças crônico-degenerativas.

A quarta receita chama-se 'Vitamina de frutas'. Do livro, é a mais fácil de se preparar. A laranja e o mamão são frutas de fácil acesso; podem ser encontradas em qualquer supermercado, feira e mercado de bairro. É uma receita que exige para sua realização um eletrodoméstico, o liquidificador, por isso um adulto deve estar por perto. Essa vitamina não leva açúcar, possibilitando que o doce natural das frutas sobressaia do sabor final do preparo. Outro detalhe é a utilização do leite em pó, que inviabiliza o seu consumo por pessoas alérgicas ao leite, ou com intolerância à lactose.

Na receita, Julieta explica que vitaminas são substâncias químicas essenciais, importantes para o crescimento e o desenvolvimento das crianças. As frutas, por sua vez, são apresentadas como a principal fonte de vitaminas, 
por isso devemos incluí-las em nossa alimentação diária, uma vez que nosso organismo não é capaz de produzi-las.

A quinta receita é o 'Docinho de coco', a preparação mais calórica do livro. Por possuir grandes quantidades de açúcar em razão do uso do leite condensado (313kcal a cada $100 \mathrm{~g}$ de parte comestível) e do coco (411kcal a cada $100 \mathrm{~g}$ de parte comestível), alguns poderiam questionar o porquê da sua presença no livro e do seu preparo. Acreditamos, porém, que é importante para o processo de educação alimentar ensinar as crianças que elas devem comer com moderação os alimentos mais calóricos, pois, no cotidiano, haverá situações em que essas guloseimas estarão a sua disposição, tais como festas de aniversários. Privar as crianças de tais situações, ou desses alimentos, seria cercear sua liberdade, daí a importância em abordar esse assunto para trazer mais temperança e equilíbrio nos momentos de consumir tais preparos.

As crianças gastam muita energia, então é necessário repor a energia gasta com alimentos ricos em calorias. Contudo, o seu consumo deve ser controlado para não promover obesidade, uma doença que preocupa a todos, crianças e adultos. Assim, é recomendável a ingestão controlada desses alimentos - notadamente, dos doces.

A última receita do livro é o 'Bolo de fubá', preparo que exige maior quantidade de insumos e manipulação de dois aparelhos domésticos - o forno elétrico e a batedeira. Os ingredientes são muitos fáceis de se encontrar em supermercados. É um bolo que foge dos sabores tradicionais consumidos pelas crianças - chocolate, morango e baunilha -, por isso a sua realização é interessante. A maioria das crianças desconhece o que é fubá, sua origem e sabor, tornando esse preparo uma excelente oportunidade de explorar vários sentidos e conversar sobre vários assuntos.

O bolo de fubá é um prato apreciado pelo paladar dos brasileiros, adultos ou crianças, além de ser uma preparação simples, de baixo custo e nutritiva. Utiliza o leite, rico em cálcio ( $123 \mathrm{~g}$ a cada $100 \mathrm{~g}$ de parte comestível); ovos, ricos em proteína (13,0g a cada $100 \mathrm{~g}$ de parte comestível); margarina, rica em lipídios $(67,4 \mathrm{~g}$ a cada $100 \mathrm{~g}$ de parte comestível); farinha de trigo e fubá, ricos em carboidratos $(75,1 \mathrm{~g}$ e 78,9g, respectivamente, para cada $100 \mathrm{~g}$ de parte comestível); açúcar e especiarias, como erva-doce, noz-moscada, baunilha e canela, que agregam aroma e sabor aos alimentos, além de possuírem propriedades medicinais.

Cada receita do livro pode proporcionar discussões distintas, permitindo explorar diferentes áreas pertinentes à educação alimentar, como a importância de se consumir hortaliças e frutas (patê de atum e agrião e vitamina maluca), a necessidade de se comer com moderação alimentos considerados menos saudáveis (docinho de coco), a origem dos alimentos (barquinhos de ricota e bolo de fubá) e as possibilidades de fazer lanches divertidos, saborosos e mais saudáveis (sanduíche rápido e barquinhos de ricota). 


\section{Considerações finais}

Este artigo analisou o Almanaque Maluquinho: Julieta no mundo da culinária, utilizando a análise do discurso para analisar elaborações presentes em seu texto e imagens. Não tivemos a pretensão de descobrir o sentido real escondido nas imagens do livro, mas perceber, com suporte nas diagramações utilizadas por Ziraldo, se essa publicação possibilita discussões que dizem respeito a diferentes áreas pertinentes à educação alimentar, podendo vir a ser uma estratégia para abordar tal tema com o público infantil.

Além do formato quadrinístico, chamou a atenção no livro o modo como o autor trabalha o comer e o prazer, abordando assuntos importantes, como consumismo e desperdício, além de mostrar que a cozinha pode também ser o espaço da criança e que esta pode não apenas ajudar, mas também preparar pratos deliciosos e saudáveis. Não encontramos nos diálogos 'não faça isso', 'não coma aquilo'; o livro não pretende ser um tutorial, porém uma fonte para divertimento.

É crescente o número de estratégias educativas com o objetivo de inserir os preceitos de uma alimentação saudável por meio da adoção de uma dieta equilibrada e do desenvolvimento de cartilhas educativas. Acreditamos que a literatura de Ziraldo, especificamente o Almanaque Maluquinho: Julieta no mundo da culinária, pode contribuir positivamente para essas estratégias.

Embora a referida publicação possa se apresentar como um instrumento de estímulo de sensibilização em relação ao tema alimentação e nutrição, devemos lembrar que ela é um produto não acabado, um construto sociocultural, um elemento de currículo cultural. Devem-se considerar suas limitações - e ao ser utilizada, é preciso se questionar acerca de suas peculiaridades e sua adequação à cultura alimentar local. Por esse motivo, a quem for utilizar o livro recomendamos cuidado e uma aproximação reflexiva sobre esse material, considerando-o como um produto cultural, marcado pelas relações de poder e ideologias. Que o considere como um recurso didático limitado, jamais que o tenha como 'uma cartilha'. 


\section{Colaboradores}

Cláudia Sales de Alcântara desenvolveu a pesquisa na escola, tabulou os achados e escreveu o texto. José Arimatea Barros Bezerra orientou o trabalho em questão, além de colaborar na construção do referencial teórico e acompanhar todo o processo do trabalho de campo. Bezerra fez também a revisão final do texto.

Resumen Actualmente, las historietas son tratadas como herramienta didáctica y pedagógica muy eficaz, con capacidad, mediante su bagaje cultural, de divertir, sentir, vivir y comportarse en el mundo. Este artículo busca investigar el libro Almanaque Maluquinho: Julieta en el mundo de la culinaria, reconociendo el papel pedagógico de las historietas, a fin de percibir si esta publicación permite discusiones que exploren diferentes áreas pertinentes a la educación alimentaria, pudiendo transformarse en una estrategia para la sensibilización del tema entre el público infantil. Utilizamos el análisis del discurso por tratarse de una herramienta metodológica que nos guía en la interpretación de los sentidos de un texto/imagen. El análisis se dio en tres etapas: análisis del contexto narrativo, por medio del cual se trató de comprender el contexto en que los personajes del libro se insertan; análisis de las historietas, para una mejor comprensión de los elementos de imagen presentes en las historietas; y análisis de las recetas, que evaluó cada preparación contenida en el libro, de modo de percibir su colaboración en la discusión de la educación alimentaria. Por fin, la investigación buscó sensibilizar la mirada hacia las posibilidades de inserción de la ludicidad en un campo del saber marcado por la prescripción.

Palabras clave educación alimentaria; nutrición; currículo cultural.

\section{Notas}

1 Universidade Federal do Ceará, Faculdade de Educação, Fortaleza, Ceará, Brasil.

<claudia.comunicacao@gmail.com>

Correspondência: Universidade Federal do Ceará, Faculdade de Educação, Rua Waldery Uchôa, Benfica, CEP 60000-000, Fortaleza, Ceará, Brasil.

2 Universidade Federal do Ceará, Faculdade de Educação, Departamento de Estudos Especializados, Fortaleza, Ceará, Brasil.

$<$ ja.bezerra@uol.com.br>

$3 \mathrm{O}$ currículo cultural possui uma compreensão que transcende o âmbito escolar, a educação formal, abraçando um conjunto de informações, valores e saberes, por intermédio de produtos culturais (televisão, jornal, revistas em quadrinhos, cinema, jogos etc.) que atravessam o cotidiano dos indivíduos e interferem em suas formas de aprender, de ver, de pensar, de sentir.

4 Pesquisa encontrada no artigo de Vergueiro (2009, p. 91), intitulado “Quadrinhos e educação popular no Brasil: considerações à luz de algumas produções nacionais". 


\section{Referências}

ALCÂNTARA, Cláudia S. Entre a razão e os sentidos, a prescrição e a experiência: Friedrich Schiller e as possibilidades de uma educação alimentar estética. 2013. 251f. Tese (Doutorado em Educação) - Programa de Pós-graduação em Educação Brasileira, Universidade Federal do Ceará, Fortaleza, Ceará, 2013.

BARBOSA, Roseane M. S.; SALLES-COSTA, Rosana; SOARES, Eliane A. Guias alimentares para crianças: aspectos históricos e evolução. Revista de Nutrição [online], Campinas, v. 19, n. 2, p. 255-263, 2006. Disponível em: <www.scielo.br/scielo.php? pid=S1415-52732006000200012\&script $=$ sci_abstract\&tlng =pt>. Acesso em: 16 jun. 2016.

BIZZO, Maria L. G.; LEDER, Lídia. Educação nutricional nos parâmetros curriculares nacionais para o ensino fundamental. Revista de Nutrição [online], Campinas, v. 18, n. 5, p. 661-667, 2005. Disponível em: $<$ www.scielo.br/scielo.php?script $=$ sci arttext\&pid=S1415-52732005000500009 > . Acesso em: 16 jun. 2016.

CAREGNATO, Rita C. A.; MUTTI, Regina. Pesquisa qualitativa: análise de discurso versus análise de conteúdo. Texto \& Contexto Enfermagem, Florianópolis, v. 15, n. 4, p. 679-684, dez. 2006.

FREITAS, Ana K. M. Psicodinâmica das cores em comunicação. Núcleo de Comunicação do ISCA Faculdades [online], Limeira, n. 12, p. 1-18, out./nov./dez. 2007. Disponível em: <www.iar.unicamp.br/lab/luz/ld/Cor/ psicodinamica_das_cores_em_comunicacao. pdf $>$. Acesso em: 16 jun. 2016.

GALVÃO, Gabriela H. Análise das histórias em quadrinhos da Mafalda e sua turma. Portal Estudo de Mídias [online], 2007. Disponível em: <www.proac.uff.br/polifonia/ sites/default/files/historiasemquadrinhos. pdf>. Acesso em: 20 mar. 2013.
MARIANI, Bethania. O PCB e a imprensa: os comunistas no imaginário dos jornais 1922-1989. Rio de Janeiro: Revan, 1998.

ORLANDI, Eni P. Análise do discurso: princípios e procedimentos. 3. ed. Campinas: Pontes, 2001.

STEINBERG, Shirley. Kindercultura: a construção da infância pelas grandes corporações. In: SILVA, Luiz H.; AZEVEDO, José C.; SANTOS, E. (orgs.). Identidade social e construção do conhecimento. Porto Alegre: SMED/RS, 1997. p. 99-145.

\section{UNIVERSIDADE ESTADUAL DE CAMPINAS} (UNICAMP). Núcleo de Estudos e Pesquisas em Alimentação (Nepa). Tabela Brasileira de Composição de Alimentos (Taco). Versão II. 2. ed. Campinas: Nepa-Unicamp, 2006.

VALDIR, Welton L. A psicodinâmica das cores como ferramenta de marketing: a percepção, influência e utilização das cores na comunicação mercadológica. 85 fls. Monografia (Curso de Administração) - Universidade Estadual de Maringá, Maringá, 2005. Disponível em: <www.iar.unicamp.br/lab/ luz/ld/Pesquisa/Psicodinamica.pdf $>$. Acesso em: 16 jun. 2016.

VERGUEIRO, Waldomiro. Quadrinhos e educação popular no Brasil: considerações à luz de algumas produções nacionais. In: VERGUEIRO, Waldomiro; SANTOS, Paulo (orgs.). Muito além dos quadrinhos: análises e reflexões sobre a $9^{\text {a }}$. arte. São Paulo: Devir, 2009. p. 85-102.

ZIRALDO. Ai, que dor de barriga! São Paulo: Melhoramentos, 1999

ZIRALDO. Tô com fome. São Paulo: Melhoramentos, 2001.

ZIRALDO. O livro de receitas do Menino Maluquinho. São Paulo: Melhoramentos, 2005. 
ZIRALDO. Almanaque Maluquinho: Julieta no mundo da culinária. São Paulo: Globo, 2008 (Coleção Almanaque Maluquinho).

ZIRALDO. O Menino Maluquinho. 92. ed. São Paulo: Melhoramentos, 2009.

ZIRALDO; ASSOCIAÇÃO DE APOIO À MERENDA ESCOLAR. Vamos cuidar da merenda escolar (cartilha). São Paulo: Globo, 2006.

ZIRALDO; LAGO, Samuel R. Turma do Laguinho: supermercado - consumo consciente. Curitiba: Nossa Cultura, 2009a (Coleção Educação em Quadrinhos).

ZIRALDO; LAGO, Samuel R. Turma do Laguinho: vivendo com saúde - os alimentos. Curitiba: Nossa Cultura, 2009b (Coleção Educação em Quadrinhos).
ZIRALDO; LANCELLOTTI, Sílvio. O livro de 'dietas' do Menino Maluquinho. São Paulo: Melhoramentos, 2004.

ZIRALDO; MINISTÉRIO DA AGRICULTURA, PECUÁRIA E ABASTECIMENTO. Olho do consumidor (cartilha). Brasília: Ministério da Agricultura, Pecuária e Abastecimento, 2009.

ZIRALDO; MINISTÉRIO DO DESENVOLVIMENTO AGRÁRIO. Secretaria de Agricultura Familiar. Escolha, freguês! A produção ecológica de alimentos já está aí! (cartilha). Brasília: Ministério do Desenvolvimento Agrário, 2005.

Recebido em 13/03/2014

Aprovado em 01/04/2015 